\title{
Article
}

\section{LIHL: Design of a Novel Loop Interlocked Hardened Latch}

\author{
Hui Xu ${ }^{1}$, Xuan Liu ${ }^{1}$, Guo Yu ${ }^{2}$, Huaguo Liang ${ }^{3, *}$ and Zhengfeng Huang ${ }^{3}$ \\ 1 College of Computer and Engineering, Anhui University of Science and Technology, Huainan 232001, China; \\ xuhui@aust.edu.cn (H.X.); liufangliuxuan@gmail.com (X.L.) \\ 2 Anhui Huainan Pingwei Power Generation Company Ltd., Huainan 232001, China; \\ smile_yuguo379@126.com \\ 3 School of Microelectronics, Hefei University of Technology, Hefei 230009, China; huangzhengfeng@139.com \\ * Correspondence: huagulg@hfut.edu.cn
}

Citation: Xu, H.; Liu, X.; Yu, G.;

Liang, H.; Huang, Z. LIHL: Design of a Novel Loop Interlocked Hardened Latch. Electronics 2021, 10, 2090.

https://doi.org/10.3390/

electronics10172090

Academic Editor: Changhwan Shin

Received: 15 July 2021

Accepted: 26 August 2021

Published: 28 August 2021

Publisher's Note: MDPI stays neutral with regard to jurisdictional claims in published maps and institutional affiliations.

Copyright: (c) 2021 by the authors. Licensee MDPI, Basel, Switzerland. This article is an open access article distributed under the terms and conditions of the Creative Commons Attribution (CC BY) license (https:/ / creativecommons.org/licenses/by/ $4.0 /)$.

\begin{abstract}
A single event causing a double-node upset is likely to occur in nanometric complementary metal-oxide-semiconductor (CMOS). Contemporary hardened latch designs are insufficient in meeting high reliability, low power consumption, and low delay. This paper presents a novel soft error hardened latch, known as a loop interlocked hardened latch (LIHL). This latch consists of four modified cross-coupled elements, based on dual interlocked storage cell (DICE) latch. The use of these elements hardens the proposed LIHL to soft errors. The simulation results showed that the LIHL has single-event double upset (SEDU) self-recoverability and single-event transient (SET) pulse filterability. This latch also reduces power dissipation and propagation delay, compared to other SEDU or SET-tolerant latches.
\end{abstract}

Keywords: soft error; single-event double-upset (SEDU); single event transient (SET); radiation hardened latch

\section{Introduction}

A soft error is generated when a particle strikes a sensitive node within a memory element—such as a latch or flip-flop_-and changes its logic values [1-3]. With the trend of decreasing technology node, the charge required to define the logic states of memory elements has become smaller, making them more susceptible to soft-errors induced by striking particles [4-6].

The main types of soft errors are single-event upset (SEU), single-event double-upset (SEDU), and single-event transient (SET). Radiation effect on circuits is more likely to occur with technology scaling [7]. Scaling increases packing densities, as well as decreases nodal charge, device spacing, and the critical charge required to upset logic values [8]. Therefore, a small amount of injected charge due to striking particles may lead to a single-event upset (SEU) and charge sharing. It may also cause internal node pairs to change state, resulting in SEDU [9-11]. Researchers have demonstrated that significant radiation could lead to an increase in soft error rates resulting from SEDU [12,13].

A particle striking a logic gate on a combinational circuit may produce a current pulse referred to as a SET. As the pulse propagates through the logic gates to a storage cell, a transient fault is produced. Researchers recently proposed a range of hardened schemes to effectively improve SEU tolerance. These schemes made use of dual-mode interlocks [14-16], guard doors [17-19], redundancy [20-22], and feedback delays [23-26]. Pulse filters can be used to filter out SET pulses [25-28]. A range of hardened schemes, based on classical Dual Interlocked Storage Cell (DICE) and tolerant SEDU, were also proposed [29-32]. SEU tolerance can also be improved through a range of layout solutions such as well isolation, increased node spacing, and redundancy. Hardened schemes increase circuit complexity, though they are better able to tolerate SEDU [13,14,33-37]. A few latch designs are cost-effective while increasing SEU, SEDU, and SET tolerance. 
This paper proposed a novel soft error hardened latch design. The proposed design used four improved cross-coupled elements based on DICE. This design is capable of self-recovering from SEU, tolerating SEDU, and filtering SET pulses. Simulation results showed SEDU and SET do not impact this latch. Section 2 of this paper reviews previous SEU and/or SEDU radiation hardened latch designs; Section 3 contains the proposed latch design and simulation results; and Section 4 presents conclusions.

\section{Previous Works}

This section reviews the typical examples of SEU and/or SEDU-tolerant latch designs such as DICE [16], FERST [27], LCHR [28], DNCS [31], HRCE [36], and LCDNUT [37].

DICE is a robust soft-error-resilient design that utilizes two interlocked latches. The interlocked structure holds state through interactions to recover single-node upsets caused by SEUs [16]. The schematic diagram is shown in Figure 1.

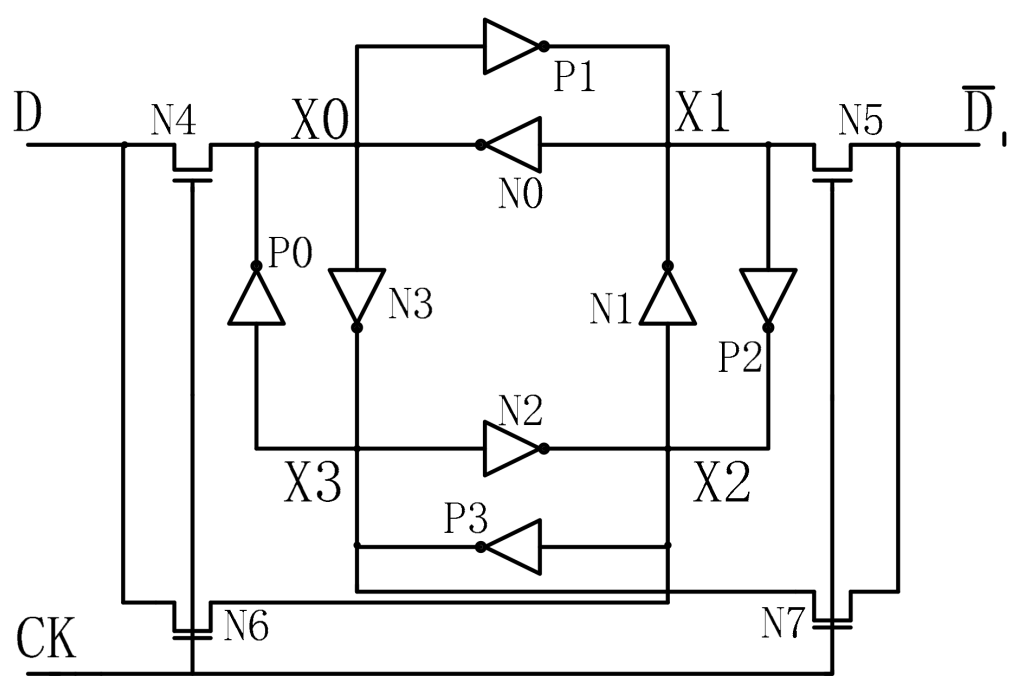

Figure 1. DICE (Dual Interlocked Storage Cell) schematic.

The latch pairs store logically complementary values. In the event of a single or adjacent node upset due to striking particles, the storage cell can recover from the upset node because of the feedback loop. However, when a strike affects non-adjacent nodes, the cell is upset due to structural limitations. A simplified double interlocking structure is shown in Figure 2.
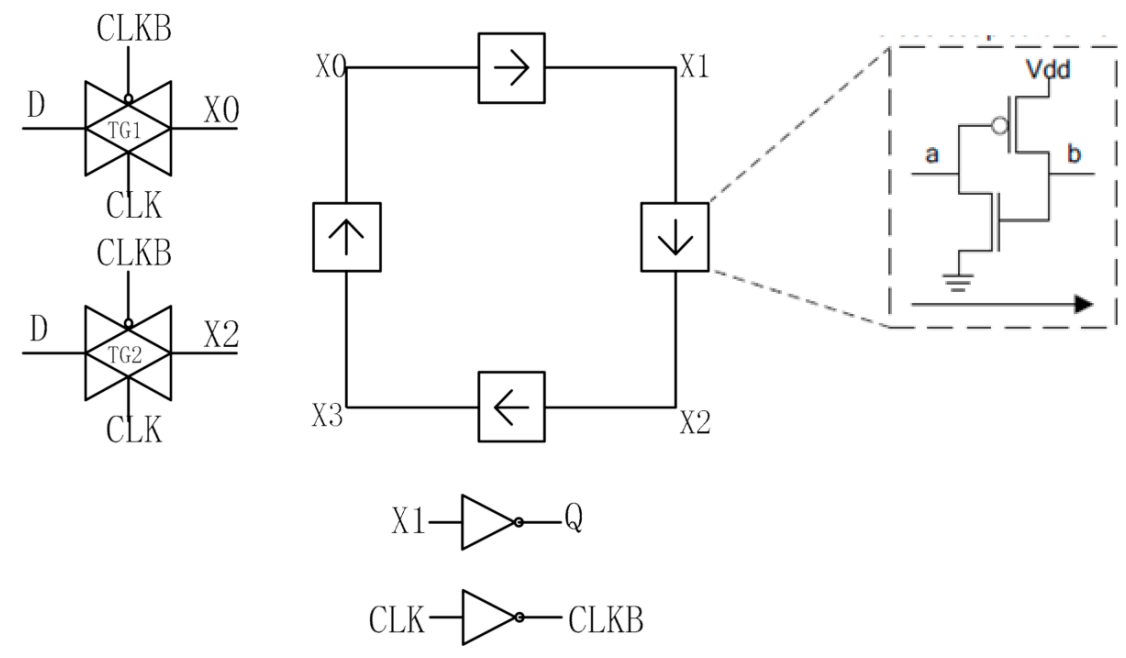

Figure 2. Simplified structure diagram of DICE. 
In the simplified structure diagram, $\mathrm{D}$ (see Figure 1) inputs logic signals to $\mathrm{X} 0$ and $\mathrm{X} 2$ through the transmission gate, and node $\mathrm{X} 1$ connects an inverter to the output $\mathrm{Q}$. Four nodes are connected through cross-coupled elements to form a dual interlocked storage structure. If input D (see Figure 1) is inverted due to an SET, X1 and X3 are also inverted, causing an output error. This means DICE is not immune to the non-adjacent node upsets, i.e., this structure cannot tolerate SEDU completely.

Figure 3 shows the schematic of the FERST [27]. The schematic uses the inverter and the two-input C-element to form the interlocked feedback loop, in which the C-element close to the output $\mathrm{Q}$ is used as a voter. This structure can tolerate SEU. When the N1 (N2) node is inverted, it can be recovered by N3 (N4) through the feedback loop; when the N3 (N4) node is inverted, the value of N1 (N2) changes through the feedback loop at the same time. This structure can tolerate SEU but cannot self-recover if the node N3 or N4 flipped.

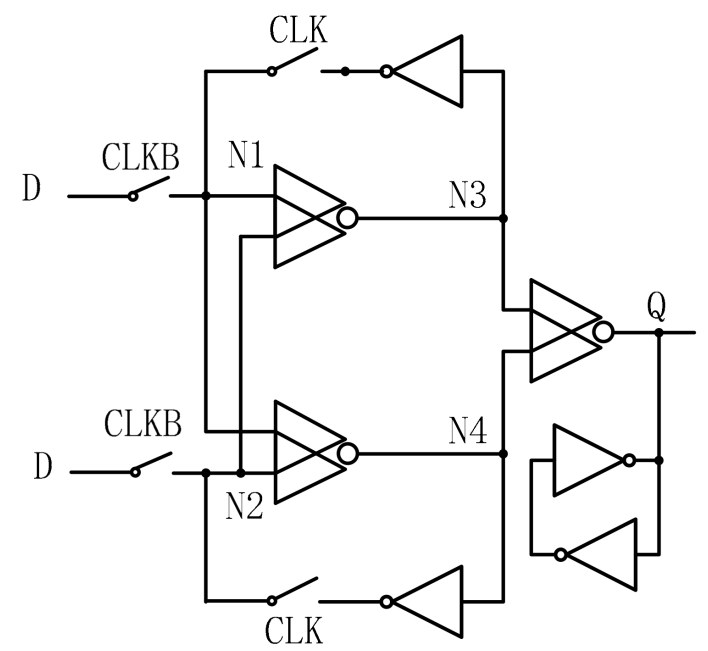

Figure 3. FERST schematic.

Figure 4 shows the schematic of the LCHR [28]. This schematic uses double modular redundancy technology to replicate the non-radiation hardened circuit and connect it to a multi-input C-element as a voter. This structure can also tolerate SEU. However, when any node in the circuit is inverted, it cannot self-recover to the original value. At the same time, this structure cannot tolerate SEDU and is sensitive to the high-impedance state.

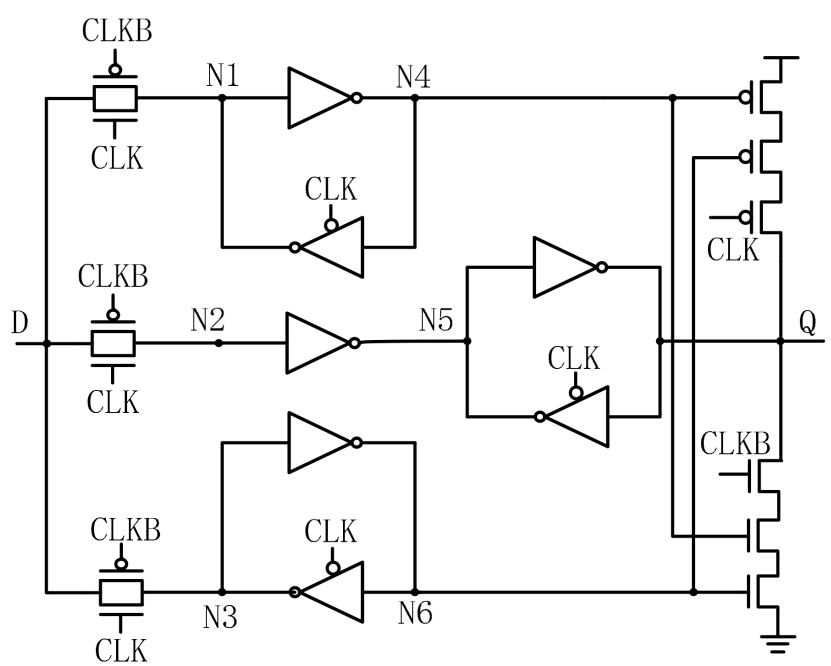

Figure 4. LCHR schematic. 
Figure 5 shows the schematic of the DNCS [31]. This schematic uses six two-input C-elements to form a feedback loop, which is connected to a three-input C-element for voting output. When the two-input nodes of a C-element are both flipped, these two nodes cannot be restored to the correct value in this case. This structure can fully tolerate SEDU; however, the structure cannot self-recover.

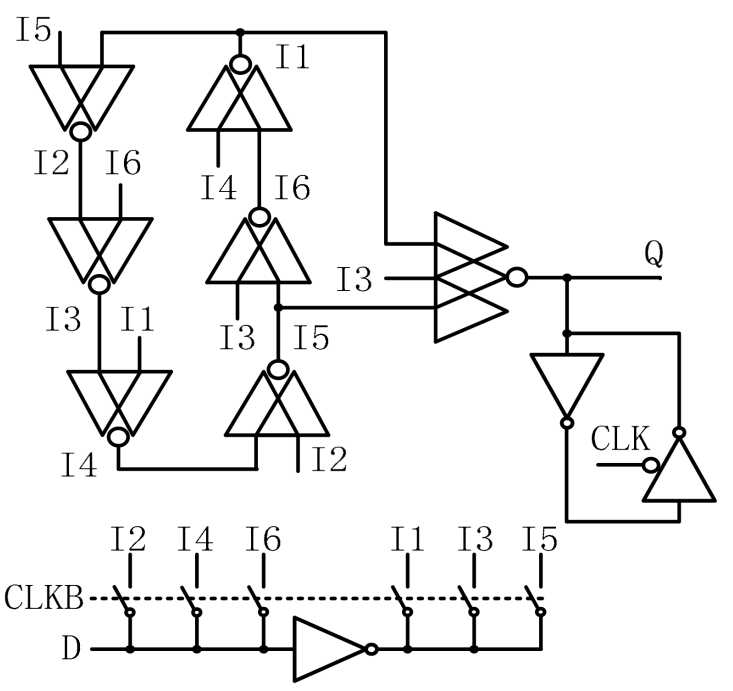

Figure 5. DNCS schematic.

Figure 6 shows the schematic of the HRCE [36]. This latch uses multi-input C-elements to form a feedback loop to store data, and uses a transmission gate to connect input and output to build a fast path to reduce delay. Due to the feedback loop, the structure can fully tolerate SEDU and self-recover, but the area of this structure is too large.

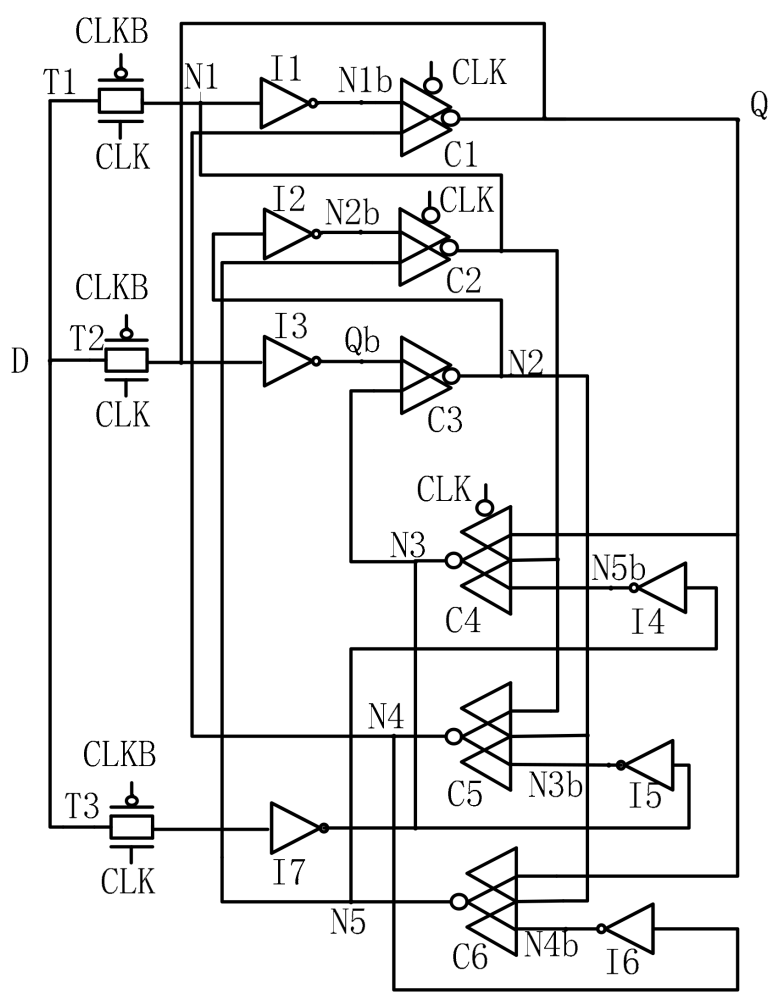

Figure 6. HRCE schematic. 
Figure 7 shows the schematic of the LCDNUT [37]. This latch is mainly constructed from a storage module in the left part and a clock-gating based error-interceptive four-input C-element in the right part. This structure also can tolerate SEDU but cannot self-recover and is sensitive to the high-impedance state.

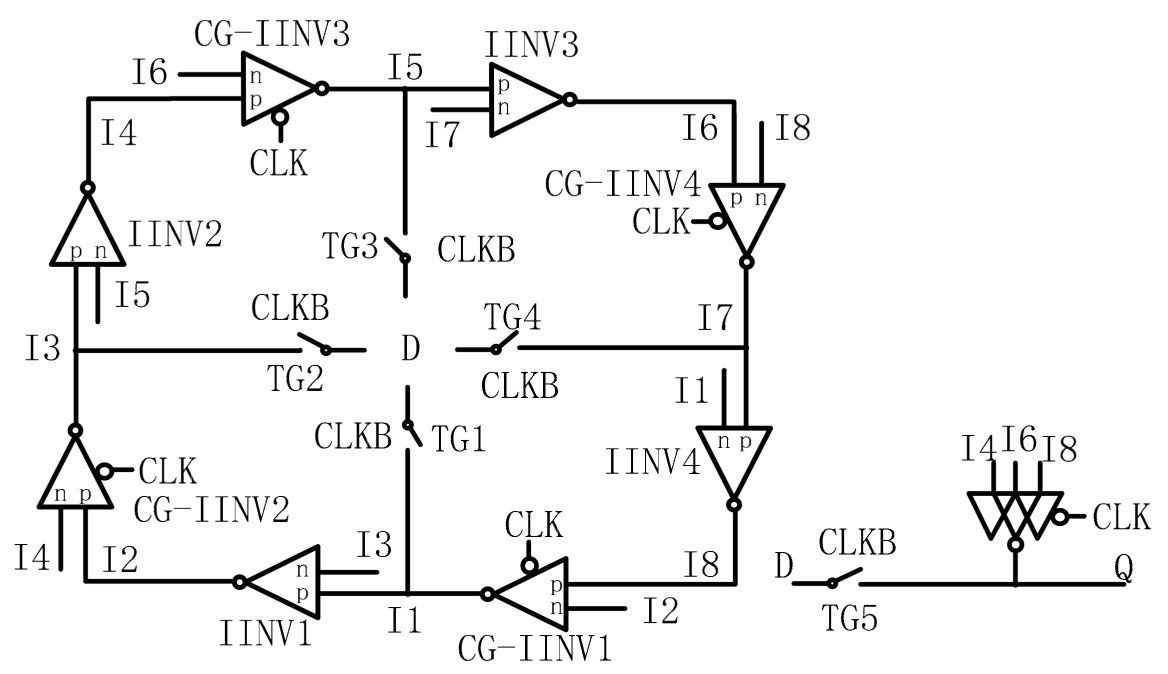

Figure 7. LCDNUT schematic.

The above schematics can tolerate SEU and/or SEDU. Some schematics can restore the flipped nodes to ensure that the output value is not affected. Most schematics use C-element as a voter since $\mathrm{C}$-element outputs high impedance state when its inputs are different because the characteristics of $\mathrm{C}$-element can prevent the propagation of errors. However, the C-element holds the high-impedance state for a long time, which will cause leakage current and will flip the output, thus generating the wrong logic value.

\section{Proposed Design and Simulation Results}

\subsection{Proposed Design}

The schematic of the proposed soft error hardened latch is presented in Figure 8. A charging structure is included. This structure consists of MP3 connected to GND, and MN3 connected to VDD. The charging structure can be used to filter SET pulse and delay SEDU, enabling fault tolerance. TG1 and TG2 are transmission gates controlled by clock (CLK) and its inverted signal (CLKB). $\mathrm{X} 1$ was connected to output $\mathrm{Q}$ through an inverter, and the loop interlocked structure comprises four cross-coupled elements (C1, C2, C3, and C4).

When CLK is high and CLKB is low, the transmission gates TG1 and TG2 are turned on, and the latch works in the transparent mode. For instance, assuming the input signal $\mathrm{D}$ is $0, X 0$ and $\mathrm{X} 2$ are controlled by the transmission gate, and both store the 0states. When node $\mathrm{X} 0$ is logic 0, MP1 and MP2 are both turned on, while MP3 is turned off. Hence, $\mathrm{X} 1$ is logic 1, and MN1 and MN2 are turned on, while MN3 is turned off. Through the cross-coupled structure, a self-latching structure $\mathrm{C} 1$ comprises $\mathrm{X} 0$ and $\mathrm{X} 1$, which can store logic values. Similarly, a self-latching structure $C 3$ comprises $X 2$ and $X 3$. Since $X 1$ is 1 and $X 2$ is 0 , the cross-coupled structure $C 2$, composed of $X 1$ and $X 2$, cannot be turned on. When the input signal D is $1, C 4$ is turned on due to $\mathrm{X} 0$ being 1 and $\mathrm{X} 3$ being 0 . Similarly, C2 is also in a self-latching state, while $\mathrm{C} 1$ and $\mathrm{C} 3$ are blocking. When the latch outputs data, the logic values are output correctly, as shown in Figure 9. 


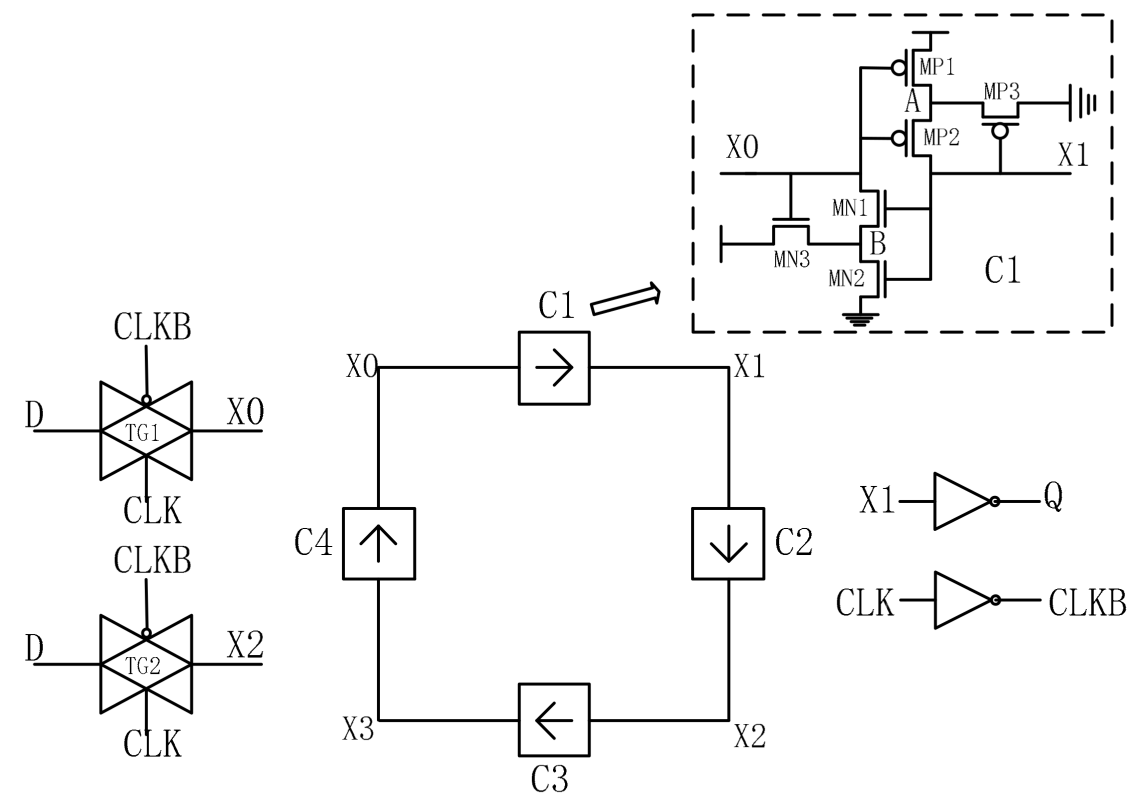

Figure 8. Proposed novel loop interlocked hardened latch (LIHL).

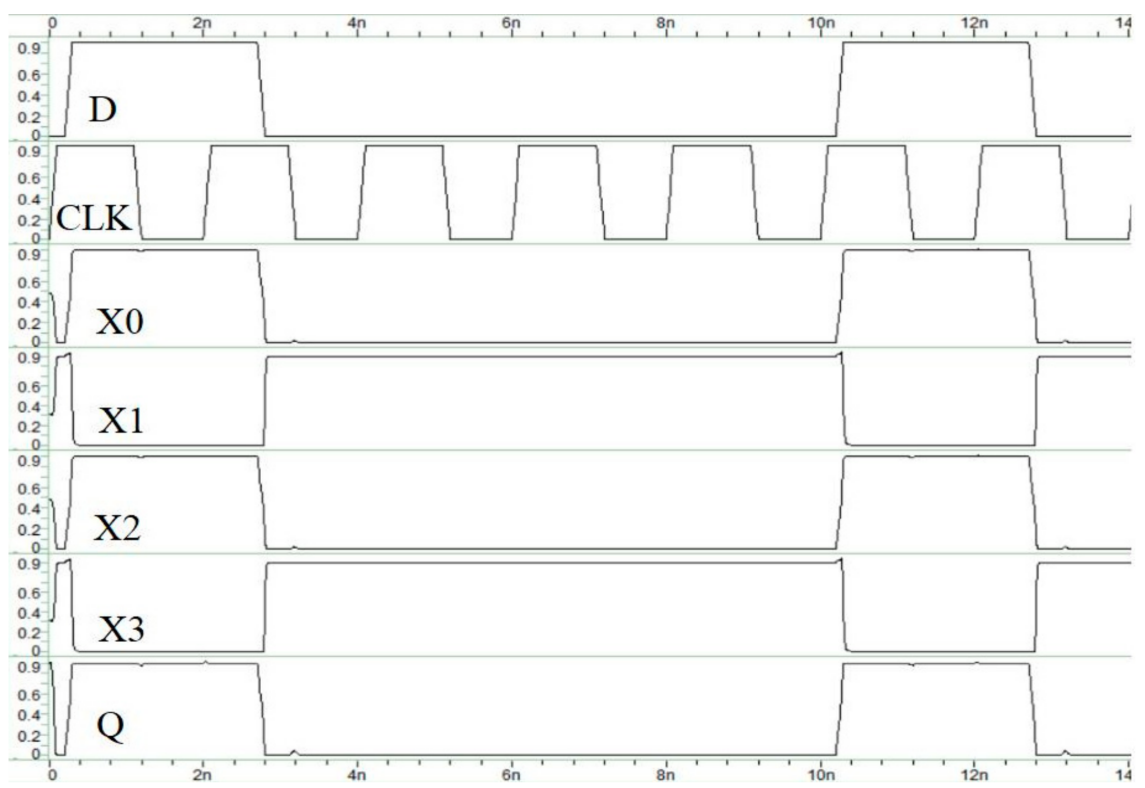

Figure 9. Simulation result under normal working condition.

The simulated LIHL was carried out with HSPICE tool using a $32 \mathrm{~nm}$ PTM [38]. The supply voltage was $0.9 \mathrm{~V}$, the temperature was $25^{\circ} \mathrm{C}$, and the clock frequency was $0.5 \mathrm{GHz}$.

\subsection{Single Node Upsets Analysis}

When CLK is low and CLKB is high, the transmission gates are off, and the latch switches to hold mode. Assuming nodes $\mathrm{X} 0, \mathrm{X} 1, \mathrm{X} 2$, and $\mathrm{X} 3$ are $0,1,0$, and 1 , respectively, SEU injections are performed, and the result is shown in Figure 10. 


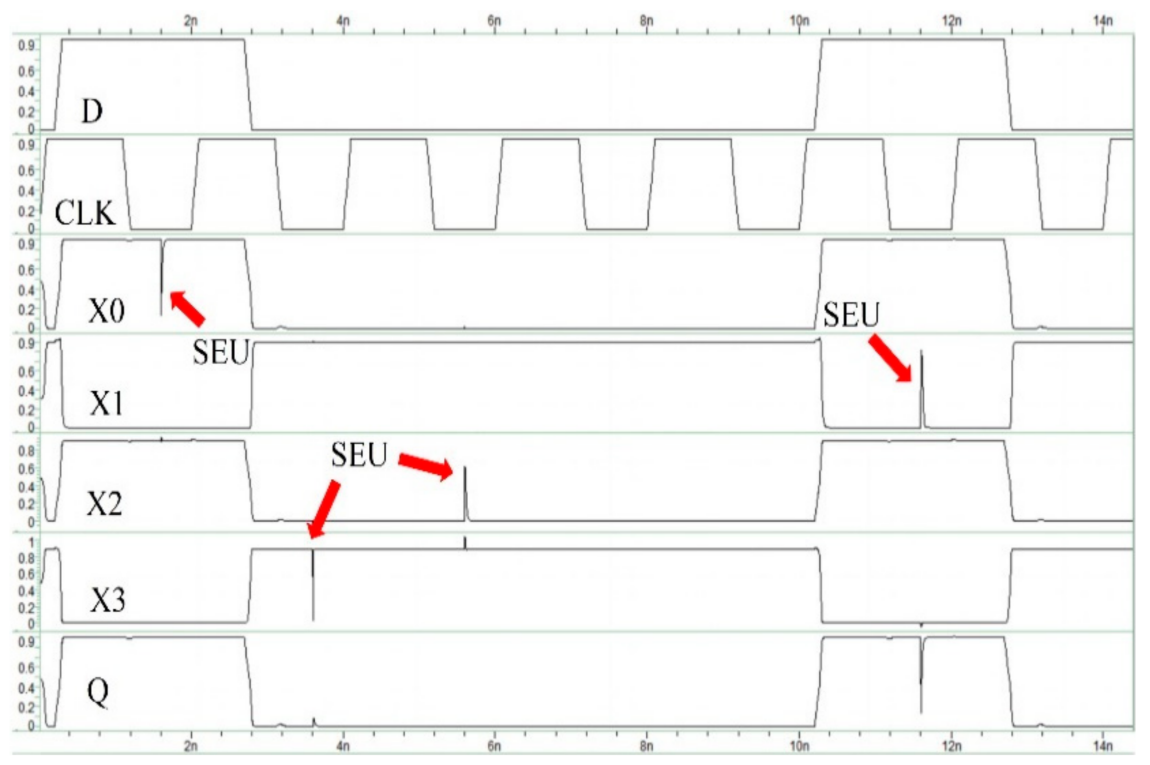

Figure 10. Simulation result during SEU injections.

When X0 was inverted, its logical value changed from 0 to 1 . MP1, MP2, and the cross-coupled structure $\mathrm{C} 1$ were then turned off, and MP3 was turned on. An n-type metal-oxide-semiconductor (NMOS) is imperfect at passing 1, while a p-type metal-oxidesemiconductor (PMOS) degrades 0. Since the PMOS was connected to GND and the NMOS to VDD, the PMOS weakened the logic signal from the MP3 path, and the logic was recovered. When TG1 and TG2 were turned on, MP3 and MN3 were also turned on, and the cross-coupled element $\mathrm{C} 4$ was in a charging state. When the value of $\mathrm{X} 0$ was changed, MN1 and MN2 were turned on, while MP3 was turned off. Due to the charge deposited during charging, if node $\mathrm{X} 3$ was to be inverted, node B must first be discharged, and X0 recovers the logic value through $\mathrm{C} 1$. This causes MN1 and MN2 to be turned off again. Similarly, when $\mathrm{X} 1, \mathrm{X} 2$, and $\mathrm{X} 3$ were inverted, the latch state was recovered through the circuit feedback.

When the nodes $\mathrm{X} 0, \mathrm{X} 1, \mathrm{X} 2$, and $\mathrm{X} 3$ were $1,0,1$, and 0 , respectively, the cross-coupled elements $\mathrm{C} 1$ and $\mathrm{C} 3$ were turned off. Node A was discharged to GND through MP3 in C1 and Node B was charged to VDD through MN3 in C1; When X0 was inverted, MN3 was turned off, MP1 and MP2 were turned on, and node A was charged. X0 was recovered from $\mathrm{X} 3$. $\mathrm{X} 1, \mathrm{X} 2, \mathrm{X} 3$, and $\mathrm{X} 0$ were similar to the state of upset to recovery.

\subsection{Double Node Upsets and SET Analysis}

In the hold state, it is assumed that the logical values of $\mathrm{X} 0, \mathrm{X} 1, \mathrm{X} 2$, and $\mathrm{X} 3$ are 0,1 , 0 , and 1 , respectively. SEDU injection was performed for $X 0$ and $X 1$, so that the values of $\mathrm{X} 0$ and $\mathrm{X} 1$ changed to 1 and 0 , respectively. When $\mathrm{C} 1$ is turned off, $\mathrm{C} 2$ and $\mathrm{C} 4$ were in a discharge state, and the charge caused by striking particles gradually decreased. Finally, the feedback of $\mathrm{X} 0$ through $\mathrm{C} 1$ was recovered, while $\mathrm{C} 4$ and $\mathrm{C} 2$ were not affected by the charging effect. $\mathrm{X} 2$ and $\mathrm{X} 3$ upsets were the same. Its fault tolerance principle is similar to the DICE structure. SEDU injection was performed on X0 and X2. Due to the delay of $\mathrm{X} 1$ and $\mathrm{X} 3$ charging, the upsets of $\mathrm{X} 0$ and $\mathrm{X} 2$ were equivalent to independent single-event upsets. The logical values of $\mathrm{X} 0$ and $\mathrm{X} 2$ were both changed from 0 to 1 . For structures that cannot be SET hardened, a logical storage error occurs. Elements C2 and C4 had to be discharged for a period of time due to the pre-charge of node $\mathrm{B}$. The logic values of $\mathrm{X} 0$ and $\mathrm{X} 2$ were recovered through the feedback loops of $\mathrm{C} 1$ and $\mathrm{C} 3$. The result is shown in Figure 11. 


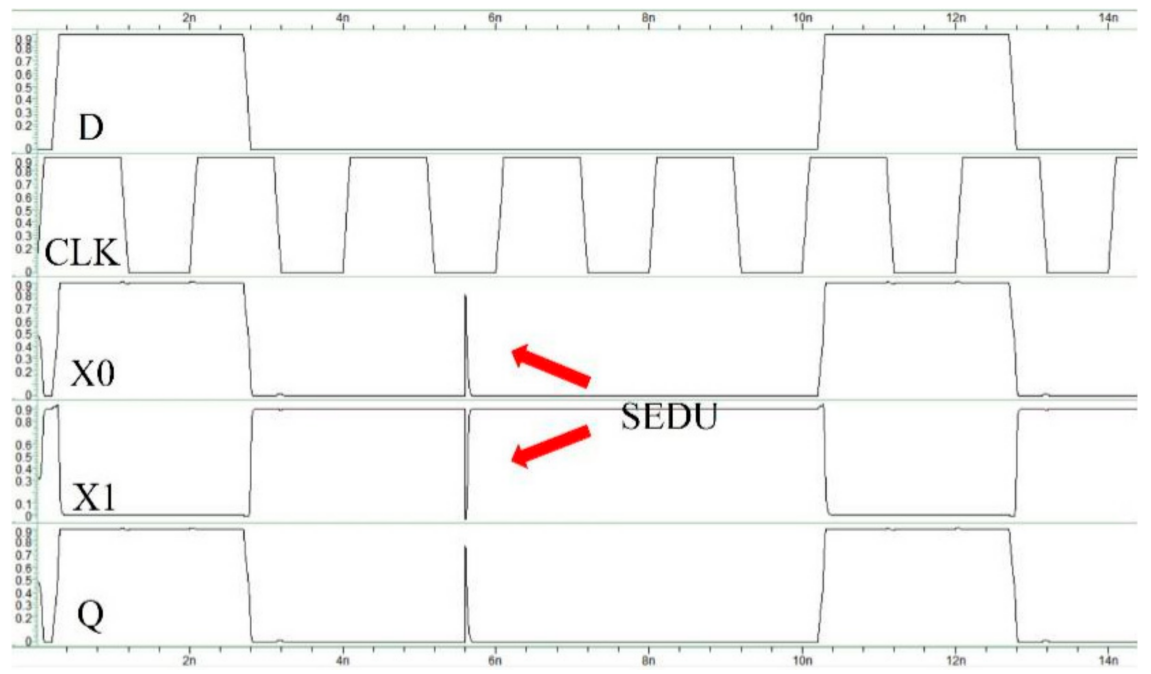

Figure 11. Simulation result during $(X 0, X 1)$ SEDU injection.

For the logic error caused by an SET, the input signal was inverted. This error first upset $X 0$ and $X 2$, and then the output value had a transient upset. As shown in Figures 12 and 13, when $\mathrm{D}$ was 0 and inverted by the transient pulse, it propagated to X0 and X2. If it was propagated to the output, node A and node B must have been discharged first. Similarly, when D was 1, it was affected by transient pulse. If this affects the output, the structure must discharge node A of the cross-coupled element $\mathrm{C} 1$. C1 was recovered because $\mathrm{X} 0$ recovered through $\mathrm{X} 3$ in a short time. The simulation result was similar to $\mathrm{X} 0$ and $\mathrm{X} 2$ upsets. Similarly, the upset of the node pairs $<\mathrm{X} 1, \mathrm{X} 3>$ was similar to $<\mathrm{X} 0, \mathrm{X} 2>$, the upset of the node pairs $<X 0, X 3>,<X 1, X 2>$ and $<X 2, X 3>$ were similar to $<X 0, X 1>$ The peak value of the fault injection was $0.9 \mathrm{~V}$, the rise time was $0.02 \mathrm{~ns}$, and the fall time was 0.1 ns.

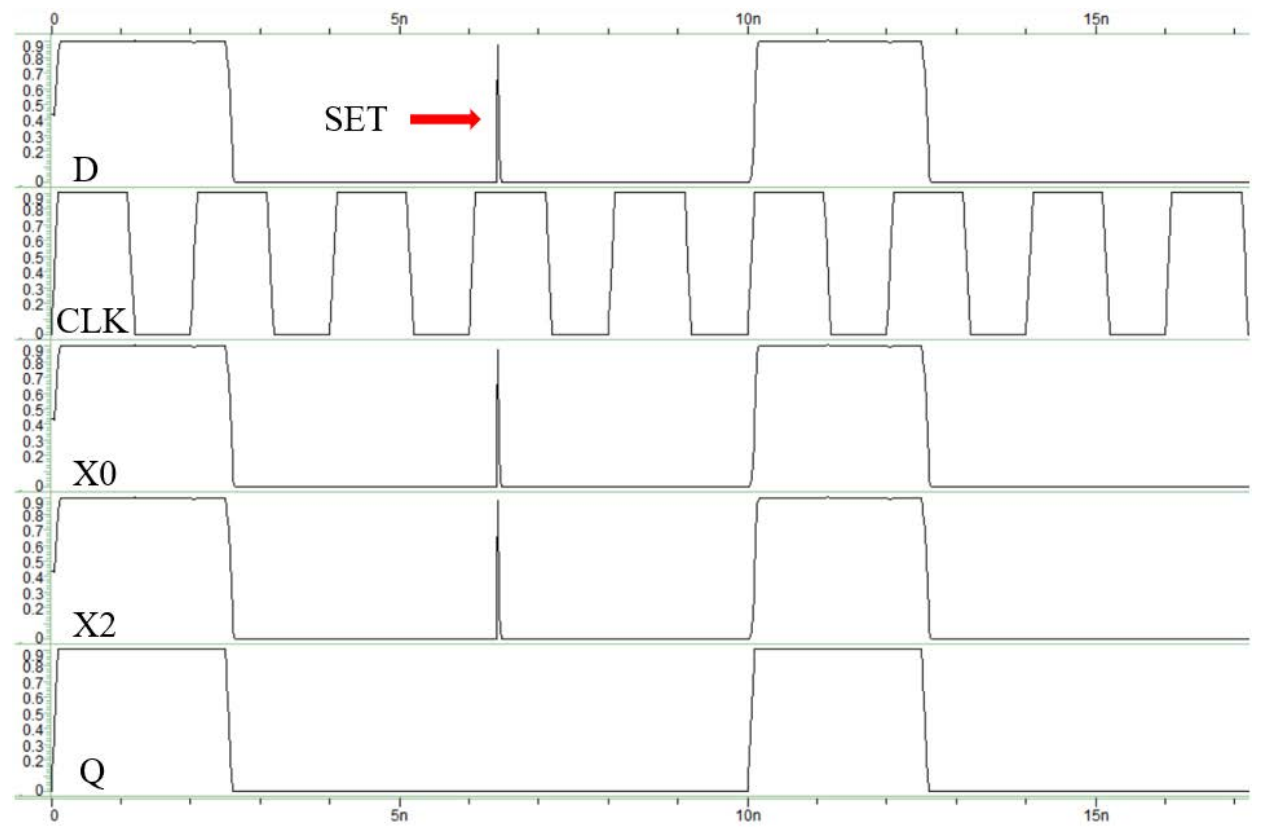

Figure 12. Simulation result during SET injection. 


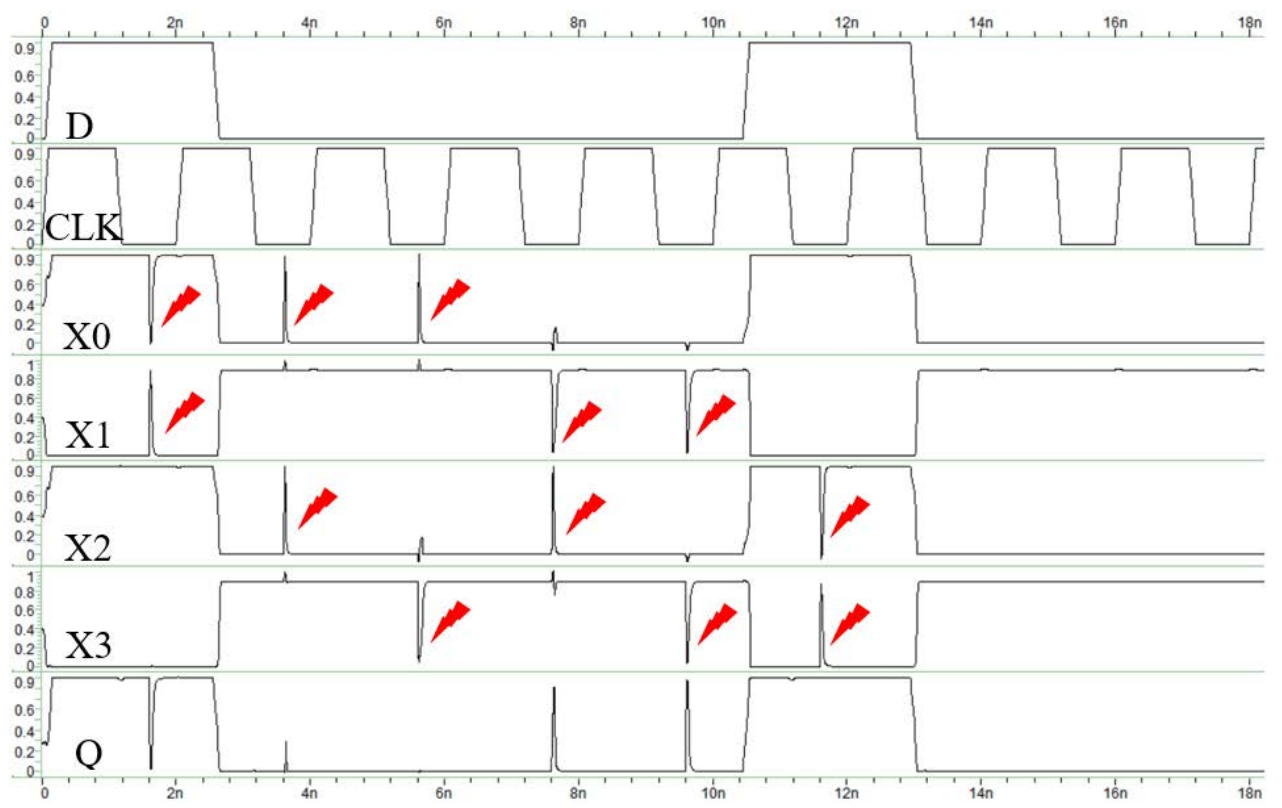

Figure 13. Simulation result during SEDU injection.

\subsection{Comparisons}

For fair comparisons, the proposed latch design and typical SEU/SEDU hardened latch designs, namely the DICE [16], FERST [27], DNCS [31], LCHR [28], HRCE [36], and LCDNUT [37] were simulated in the same technology node using the $32 \mathrm{~nm}$ PTM in [38]. The supply voltage VDD was set to $0.9 \mathrm{~V}$, the temperature was set to $25^{\circ} \mathrm{C}$, and the clock frequency was set to $0.5 \mathrm{GHz}$. The transistor sizes in these latch designs were set as follows: as for all PMOS, the transistors had W/L $=64 / 32 \mathrm{~nm}$, while the NMOS transistors had $\mathrm{W} / \mathrm{L}=32 / 32 \mathrm{~nm}$.

Table 1 compares the tolerance ability of LIHL against other classical designs. Unlike the other designs, the proposed LIHL latch can tolerate soft errors caused by SEU, SEDU, and SET.

Table 1. Examples of Different Tolerance Storage Cells.

\begin{tabular}{cccc}
\hline Latch & SEU Tolerance & SEDU Tolerance & SET Tolerance \\
\hline DICE [16] & YES & NO & NO \\
FERST [27] & YES & NO & YES \\
DNCS [31] & YES & YES & NO \\
LCHR [28] & YES & NO & YES \\
HRCE [36] & YES & YES & NO \\
LCDNUT [37] & YES & YES & NO \\
LIHL (proposed) & YES & YES & YES \\
\hline
\end{tabular}

In order to prove that the proposed LIHL design can operate under different working voltages, an HSPICE simulation was performed on the design under operating voltages of $0.7-1.1 \mathrm{~V}$. The simulation result is presented in Figure 14.

The delay, power consumption, and power delay product (PDP) of various latch designs were compared. Delay means $\mathrm{D}$ to $\mathrm{Q}$ transmission delay, i.e., the average of rise and fall delays of $\mathrm{D}$ to $\mathrm{Q}$, and power consumption means the average power consumption of the latch in book [39]. Referring to Figure 15, with exception of the DICE latch, the proposed LIHL design has the advantage of a significantly lower delay.

Figure 16 shows that, with the exception of LCHR and DICE, the proposed LIHL design has lower power consumption, compared to others, especially those with SEDU- or SET-tolerant capacity. 


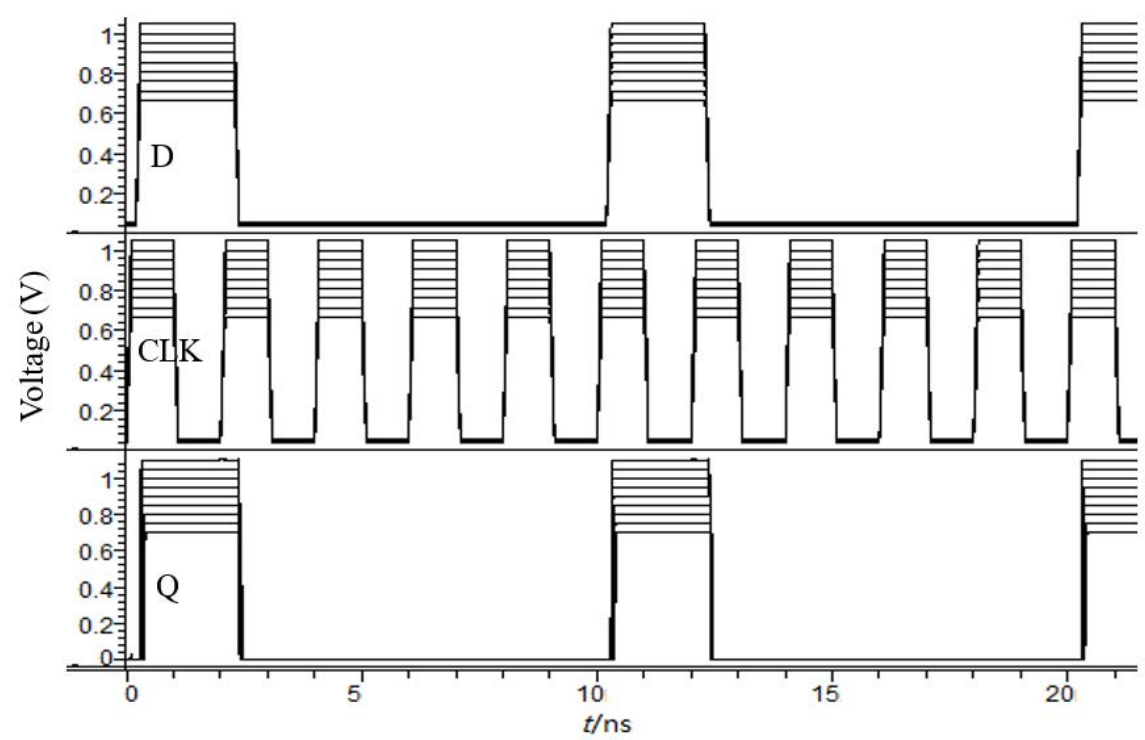

Figure 14. Design simulation under working voltages of $0.7-1.1 \mathrm{~V}$.

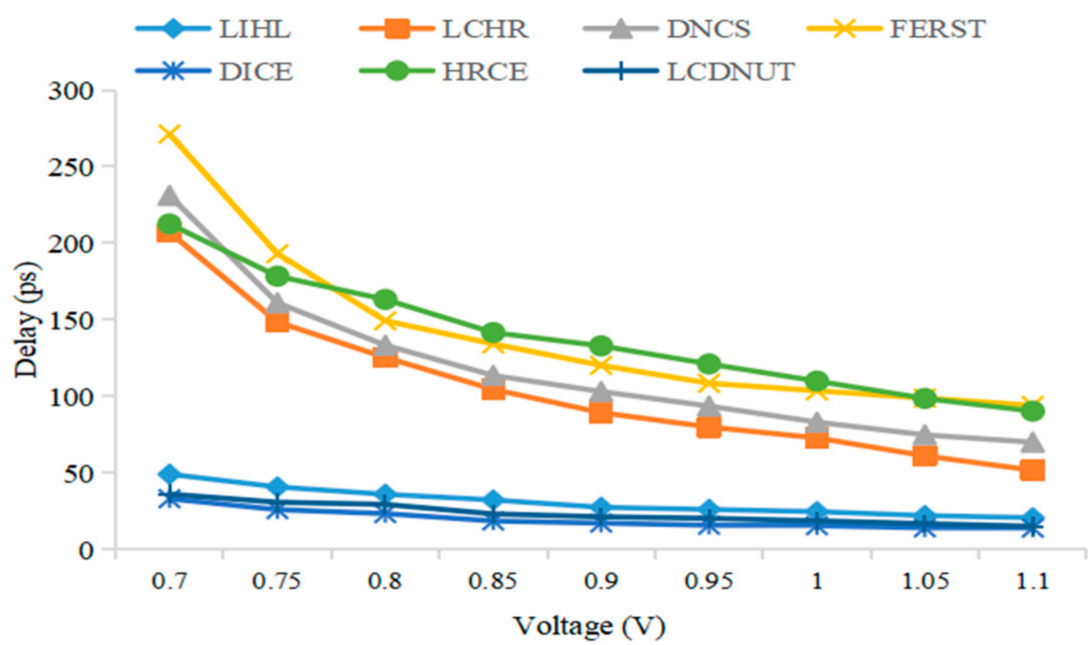

Figure 15. Delay comparison of various latch designs under different voltages.

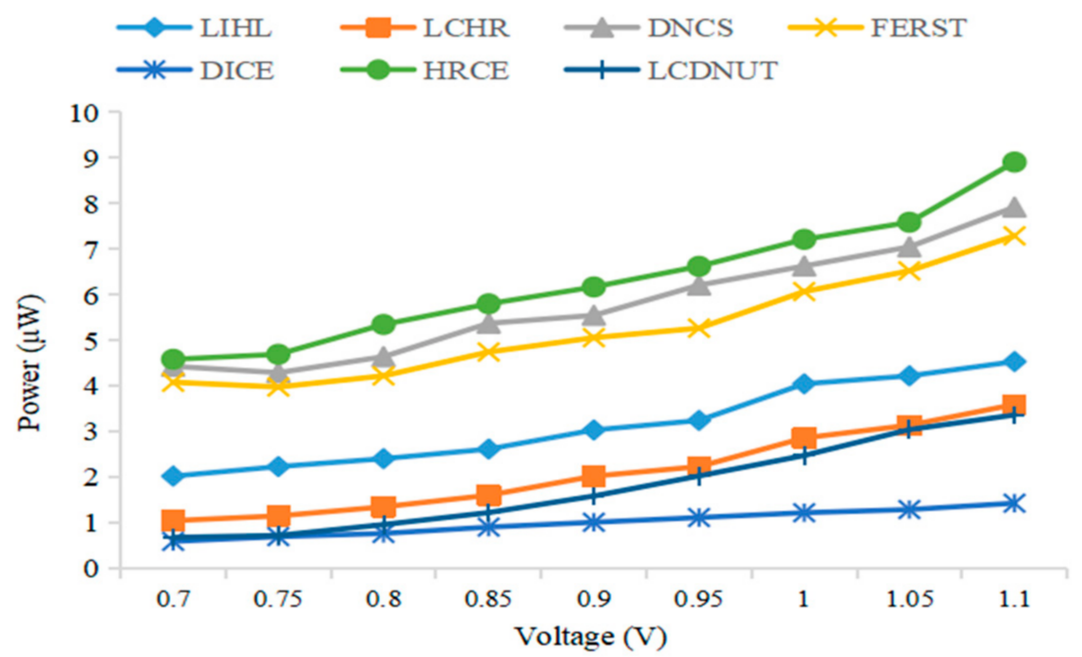

Figure 16. Power consumption of various latch designs under different voltages. 
Figure 17 compares the PDP of the proposed LIHL design against those of other latch designs. The LIHL PDP is reasonably low, indicating that the design can tolerate soft errors while maintaining low power consumption and propagation delay.

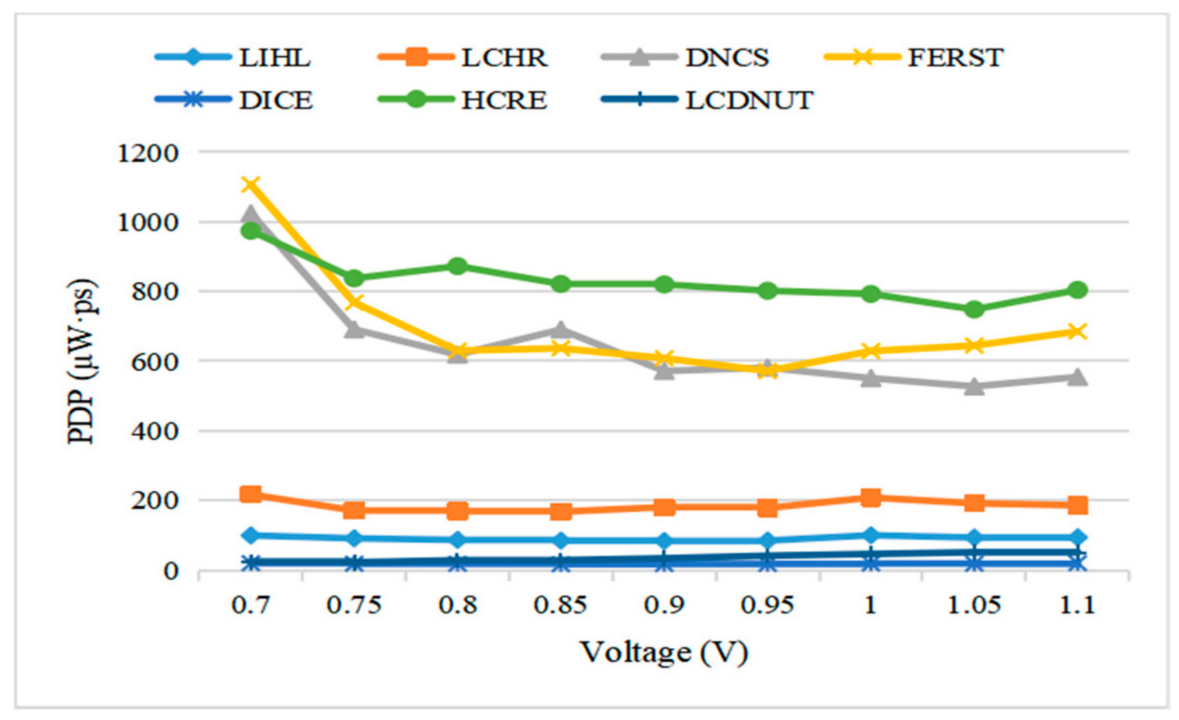

Figure 17. PDP of various latch designs under different voltages.

Figures 18 and 19 show the experimental results of the effect of temperature changes on the delay and power of the latch. The normal temperature is set to $25^{\circ} \mathrm{C}$, and the temperature varies from $-25^{\circ} \mathrm{C}$ to $55^{\circ} \mathrm{C}$. It can be seen from the experimental results that the HRCE latch and the DNCS latch are more sensitive to temperature changes, and the power consumption and delay fluctuate greatly; meanwhile, DICE, LCDNUT, and the proposed latch are not sensitive to temperature, and the power consumption and delay fluctuation are more stable.

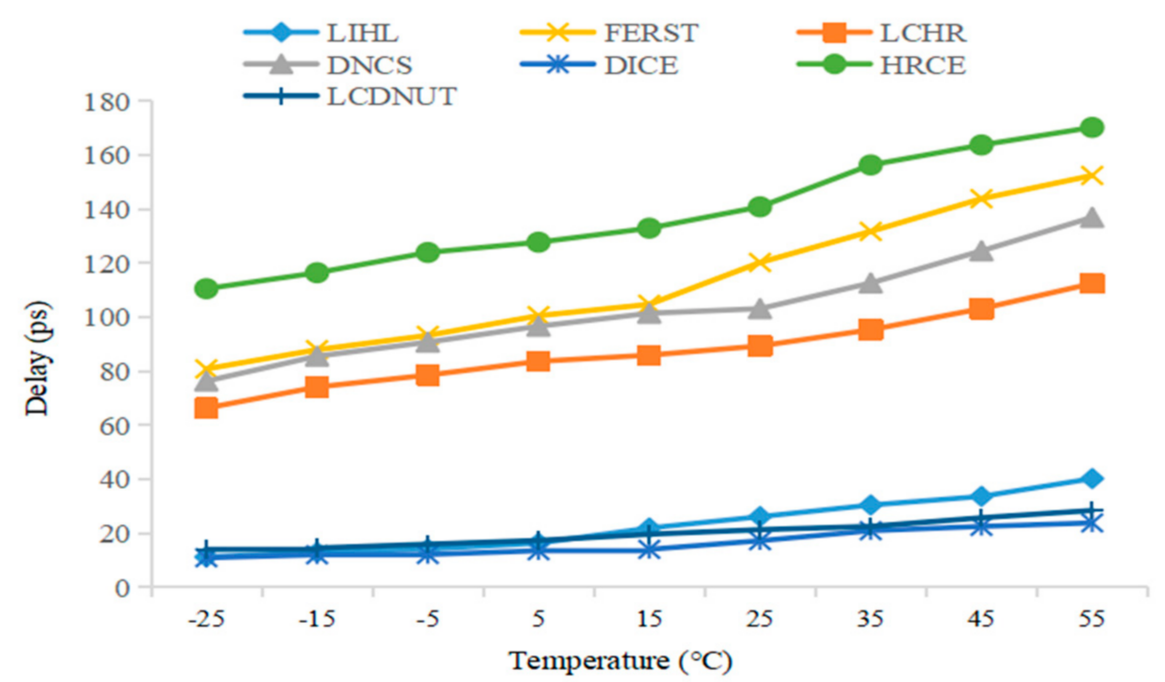

Figure 18. Delay comparison of various latch designs under different temperatures.

Figures 20 and 21 show the effect of the threshold voltage $\left(V_{t h}\right)$ on the delay and power of the latches. The $\mathrm{V}_{\mathrm{th}}$ of the NMOS transistor is set from -0.5088 to -0.5888 . Through the experimental result, it can be seen that the delay of all latch is less sensitive to the $V_{\text {th }}$ changes, and basically maintains a stable state; the HRCE and FERST latches are highly sensitive to the $\mathrm{V}_{\text {th }}$ on power consumption. The power consumption and delay of the latch structure proposed in this paper are relatively stable, and the fluctuation is slight. 


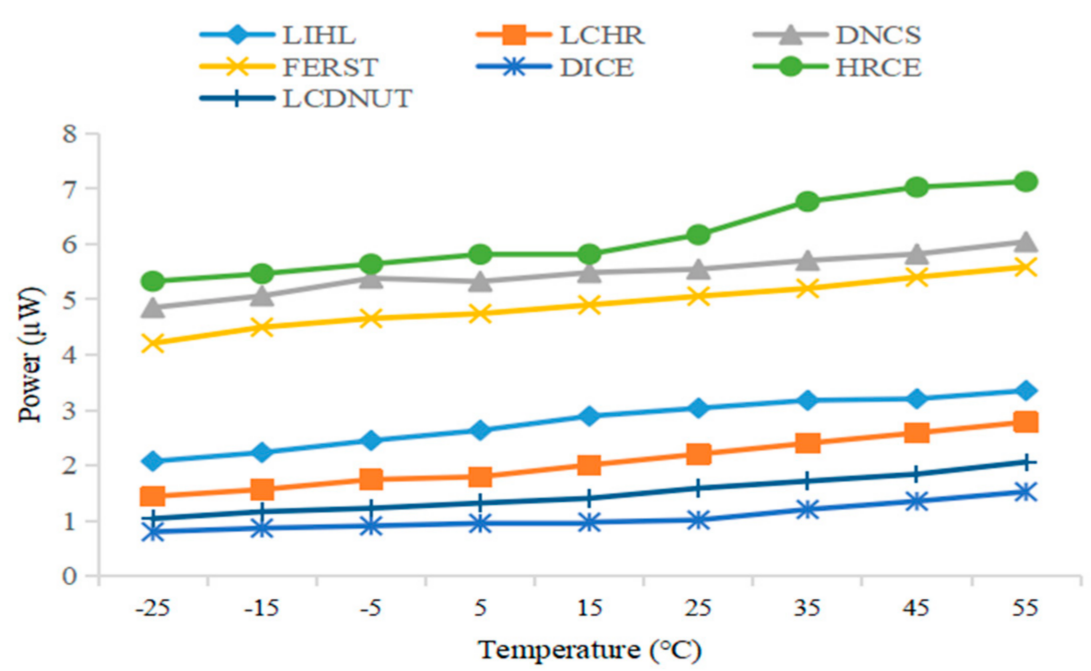

Figure 19. Power consumption of various latch designs under different temperatures.

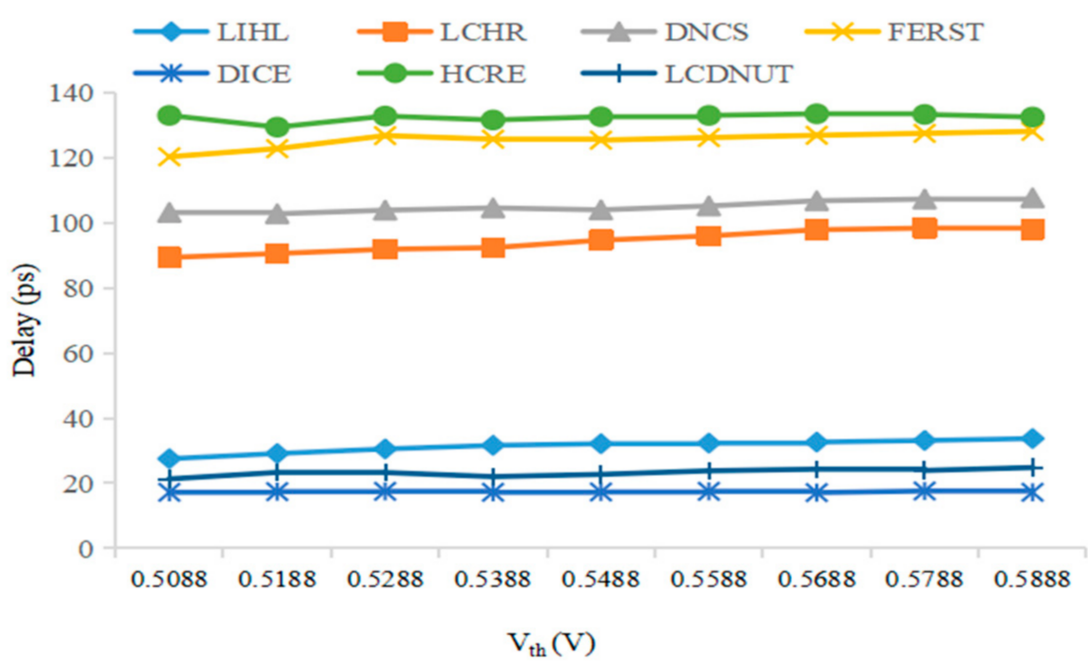

Figure 20. Delay comparison of various latch designs under different $V_{\text {th }}$.

The power consumption, delay, and PDP of the proposed LIHL design can be compared against others using this formula:

$$
\Delta=\text { (proposed latch-compared latch)/(compared latch), }
$$

Table 2 shows the value of power, delay, and PDP of the LIHL design and other latch designs; Table 3 shows the value of area and $\Delta$ area; and Figure 22 shows that $\Delta$ power, $\Delta$ delay and $\triangle \mathrm{PDP}$ of various latch designs compared to the proposed latch. $\Delta$ means the percentage change of the compared latch and the latch proposed in this paper. In Figure 22 and Table 3, negative values denote that the proposed latch has advantages. From Figure 22, DICE latch and LCDUNT latch have lower power, delay and PDP, but DICE latch is not completely SEDU-tolerant and from Table 3, LCDUNT latch has a larger area than the proposed latch. It also can be seen that LIHL has a lower area compared with other SEDU-tolerant and/or SEDU-recovered latches. In the area-critical field, the LIHL latch is competitive. 


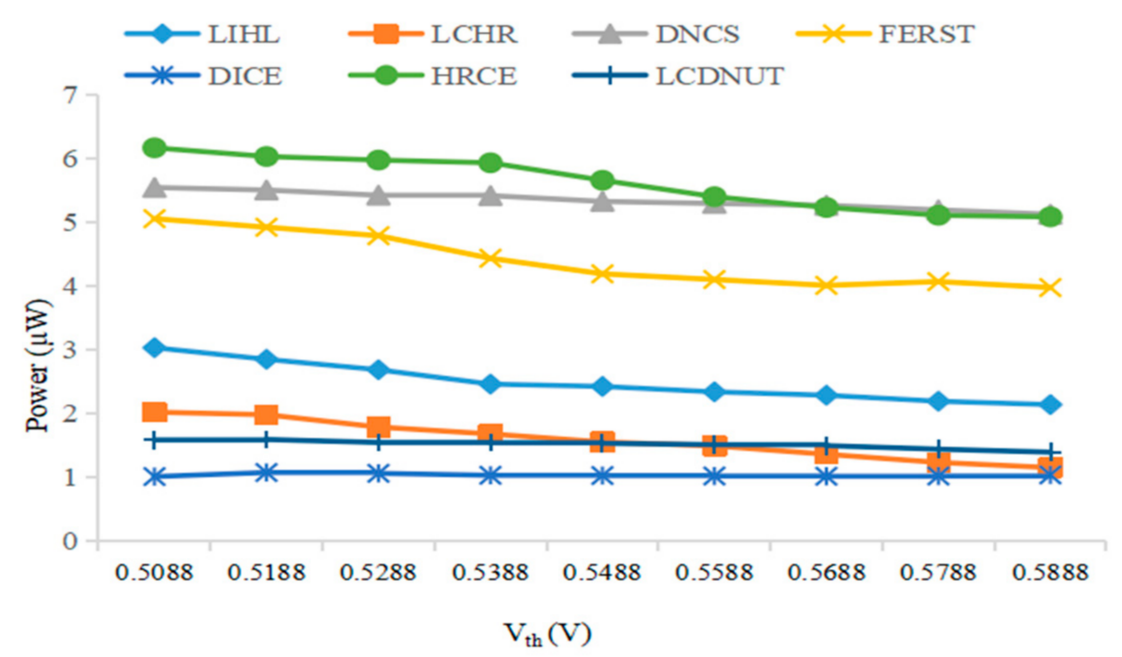

Figure 21. Power consumption of various latch designs under different $\mathrm{V}_{\text {th }}$.

Table 2. Power, Delay, and PDP Comparison at $0.9 \mathrm{~V}$.

\begin{tabular}{cccc}
\hline Latch & Power $(\mu \mathbf{W})$ & Delay $(\mathbf{p s})$ & PDP $(\mu \mathbf{\mu} \cdot \mathbf{p s})$ \\
\hline DICE [16] & 0.973 & 17.2 & 16.736 \\
FERST [27] & 4.901 & 120.2 & 589.100 \\
DNCS [31] & 5.486 & 103.1 & 565.607 \\
LCHR [28] & 2.007 & 89.3 & 179.225 \\
HRCE [36] & 6.170 & 140.8 & 868.736 \\
LCDNUT [37] & 1.587 & 21.3 & 33.803 \\
LIHL (proposed) & 2.890 & 26.1 & 75.429 \\
\hline
\end{tabular}

Table 3. Area Comparison.

\begin{tabular}{ccccc}
\hline Latch & Area $\left(\boldsymbol{\mu \mathbf { m } ^ { 2 }}\right)$ & $\Delta$ Area & SEDU Tolerant & SEDU Recovered \\
\hline DICE [16] & 2.15 & $114.42 \%$ & No & No \\
FERST [27] & 4.30 & $7.21 \%$ & No & No \\
DNCS [31] & 6.76 & $-31.80 \%$ & Yes & No \\
LCHR [28] & 4.92 & $-6.30 \%$ & No & No \\
HRCE [36] & 8.60 & $-46.40 \%$ & Yes & Yes \\
LCDNUT [37] & 6.45 & $-28.53 \%$ & Yes & No \\
LIHL (proposed) & 4.61 & - & Yes & Yes \\
\hline
\end{tabular}

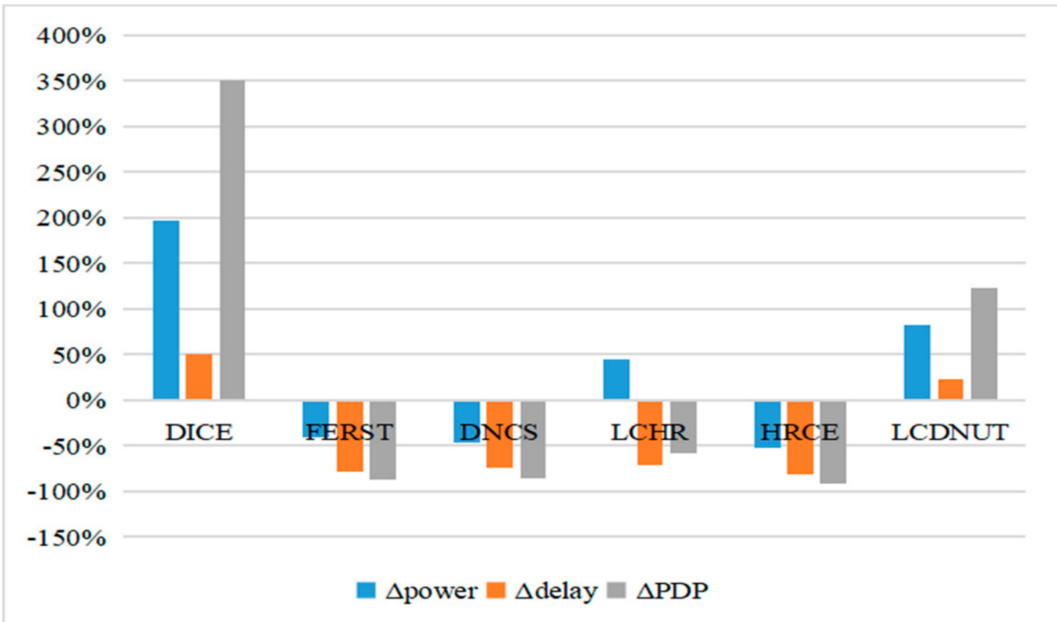

Figure 22. $\Delta$ power, $\Delta$ delay, and $\triangle \mathrm{PDP}$ of various latch designs compare to the proposed. 


\section{Conclusions}

Aiming for soft errors tolerance, this paper proposed a novel LIHL. Simulation results showed that the design could effectively tolerate soft errors. Compared with DICE, which is only capable of SEU tolerance, LIHL has the capacity for SEU, SEDU, and SET tolerance. Compared with the DNCS and HRCE designs, LIHL power consumption is reduced by $86.31 \%$ and $91.07 \%$, respectively. Compared with the LCDNUT designs, LIHL power consumption is increased by $82 \%$ and the delay is similar, but the LIHL area is reduced by $28.53 \%$. Compared to existing radiation hardened latches, LIHL has better performance with lower area, power consumption, and delay. With CMOS technology aggressively scaling down, integrated circuits are becoming vulnerable to radiation-induced errors. The probability of the multiple node upset is gradually increasing. Due to the better performance and lower overhead of this structure, multiple-node upset-tolerant latches can be designed with this structure in future work [40].

Author Contributions: Conceptualization, H.X. and X.L.; software, X.L.; validation, G.Y. and Z.H.; formal analysis, Z.H.; writing-original draft preparation, H.X.; writing-review and editing, H.L.; supervision, H.L.; project administration, Z.H.; funding acquisition, H.L. All authors have read and agreed to the published version of the manuscript.

Funding: This work was supported in part by the Special Fund for Research on National Major Research Instruments of China under Grant 62027815, the National Natural Science Foundation of China under Grant 61834006, 61674048, 61874156 and 61404001.

Conflicts of Interest: The authors declare no conflict of interest.

\section{References}

1. Gadlage, M.J.; Roach, A.H.; Duncan, A.R.; Williams, A.M.; Bossev, D.P.; Kay, M.J. Soft errors induced by high energy electrons. IEEE Trans. Device Mater. Reliab. 2017, 17, 157-162. [CrossRef]

2. Zhang, H.; Jiang, H.; Assis, T.R.; Ball, D.R.; Narasimham, B.; Anvar, A.; Massengill, L.W.; Bhuva, B.L. Angular Effects of Heavy-Ion Strikes on Single-Event Upset Response of Flip-Flop Designs in 16-nm Bulk FinFET Technology. IEEE Trans. Nucl. Sci. 2017, 64, 491-496. [CrossRef]

3. Zhang, H.; Jiang, H.; Assis, T.R.; Mahatme, N.N.; Narasimham, B.; Massengill, L.W.; Bhuva, B.L.; Wen, S.; Wong, R. Effects of Threshold Voltage Variations on Single-Event Upset Response of Sequential Circuits at Advanced Technology Nodes. IEEE Trans. Nucl. Sci. 2017, 64, 457-463. [CrossRef]

4. Gill, B.; Seifert, N.; Zia, V. Comparison of alpha particle and neutron-induced combinational and sequential logic error rates at the $32 \mathrm{~nm}$ technology node. In Proceedings of the IEEE International Reliability Physics Symposium, Montreal, QC, Canada, 26-30 April 2009; pp. 199-205. [CrossRef]

5. Anjan, S.; Maryam, B. Robust soft error tolerant CMOS latch configurations. IEEE Trans. Comput. 2016, 65, 2820-2834. [CrossRef]

6. Gill, B.S.; Papachristou, C.; Wolff, F.G.; Seifert, N. Node sensitivity analysis for soft errors in CMOS logic. In Proceedings of the IEEE International Conference on Test, Austin, TX, USA, 8-8 November 2005; pp. 1-9. [CrossRef]

7. Yan, A.; Yang, K.; Huang, Z.; Zhang, J.; Cui, J.; Fang, X.; Yi, M.; Wen, X. A double-node-upset self-recoverable latch design for high performance and low power application. IEEE Trans. Circuits Syst. II Express Briefs 2019, 66, 287-291. [CrossRef]

8. Jagannathan, S.; Loveless, T.D.; Bhuva, B.L.; Wen, S.; Wong, R.; Sachdev, M.; Rennie, D.; Massengill, L.W. Single-event tolerant flip-flop design in 40nm bulk CMOS technology. IEEE Trans. Nucl. Sci. 2011, 58, 3033-3037. [CrossRef]

9. Baumann, R.C. Radiation-induced soft errors in advanced semiconductor technologies. IEEE Trans. Device Mater. Reliab. 2005, 5, 305-316. [CrossRef]

10. Chandra, V.; Aitken, R. Impact of voltage scaling on nanoscale SRAM reliability. In Proceedings of the Design, Automation \& Test in Europe Conference \& Exhibition, Nice, France, 20-24 April 2009; pp. 387-392. [CrossRef]

11. Rajaei, R.; Asgari, B.; Tabandeh, M.; Fazeli, M. Design of robust SRAM cells against single-event multiple effects for nanometer technologies. IEEE Trans. Device Mater. Reliab. 2015, 15, 429-436. [CrossRef]

12. Black, J.; Dodd, P.; Warren, K. Physics of multiple node charge collection and impacts on single-event characterization and soft error rate prediction. IEEE Trans. Nucl. Sci. 2013, 60, 1836-1851. [CrossRef]

13. Yamamoto, Y.; Namba, K. Construction of Latch Design with Complete Double Node Upset Tolerant Capability Using C-Element. In Proceedings of the International Symposium on Defect and Fault Tolerance in VLSI and Nanotechnology Systems, Chicago, IL, USA, 8-10 October 2018; pp. 8-10. [CrossRef]

14. Guo, J.; Zhu, L.; Liu, W.; Huang, H.; Liu, S.; Wang, T.; Xiao, L.; Mao, Z. Novel radiation-hardened-by-design (RHBD) 12 T memory cell for aerospace applications in nanoscale CMOS technology. IEEE Trans. Very Large Scale Integr. Syst. 2017, 25, 1593-1600. [CrossRef]

15. Huang, Z.; Liang, H.; Hellebrand, S. A high performance SEU tolerant latch. J. Electron. Test. 2015, 31, 349-359. [CrossRef] 
16. Calin, T.; Nicolaidis, M.; Velazco, R. Upset hardened memory design for submicron CMOS technology. IEEE Trans. Nucl. Sci. 1996, 43, 2874-2878. [CrossRef]

17. Alioto, M.; Consoli, E.; Palumbo, G. Variations in nanometer CMOS flip-flops: Part I-impact of process variations on timing. IEEE Trans. Circuits Syst. I Regul. Pap. 2015, 62, 2035-2043. [CrossRef]

18. Omana, M.; Rossi, D.; Metra, C. High-performance robust latches. IEEE Trans. Comput. 2010, 59, 1455-1465. [CrossRef]

19. She, X.; Li, N.; Tong, J. SEU tolerant latch based on error detection. IEEE Trans. Nucl. Sci. 2012, 59, 211-214. [CrossRef]

20. Mitra, S.; Zhang, M.; Seifert, N.; Mak, T.; Kim, K.S. Built-in soft error resilience for robust system design. In Proceedings of the IEEE International Conference on Integrated Circuit Design and Technology, Austin, TX, USA, 30 May-1 June 2007; pp. 1-6. [CrossRef]

21. She, X.; Mcelvain, K. Time multiplexed triple modular redundancy for single event upset mitigation. IEEE Trans. Nucl. Sci. 2009, 56, 2443-2448. [CrossRef]

22. Yan, A.; Liang, H.; Huang, Z.; Jiang, C.; Yi, M. A self-recoverable, frequency-aware and cost-effective robust latch design for nanoscale CMOS technology. IEICE Trans. Electronic 2015, 98, 1171-1178. [CrossRef]

23. Shah, J.; Nairn, D.; Sachdev, M. A 32 kb macro with 8 T soft error robust, SRAM cell in 65nm CMOS. IEEE Trans. Nucl. Sci. 2015, 62, 1367-1374. [CrossRef]

24. Wang, H.; Chen, L.; Liu, R.; Li, Y.; Kauppila, J.S.; Bhuva, B.L.; Lilja, K.; Wen, S.; Wong, R.; Fung, R.; et al. An Area Efficient Stacked Latch Design Tolerant to SEU in 28 nm FDSOI Technology. IEEE Trans. Nucl. Sci. 2016, 63, 3003-3009. [CrossRef]

25. Alidash, H.K.; Oklobdzija, V. Low-power soft error hardened latch. J. Low Power Electron. 2010, 6, 218-226. [CrossRef]

26. Rajaei, R.; Tabandeh, M.; Fazeli, M. Low cost soft error hardened latch designs for nano-scale CMOS technology in presence of process variation. Microelectron. Reliab. 2013, 53, 912-924. [CrossRef]

27. Fazeli, M.; Miremadi, S.G.; Ejlali, A.; Patooghy, A. Low energy single event upset/single event transient-tolerant latch for deep submicron technologies. IET Comput. Digit. Tech. 2009, 3, 289-303. [CrossRef]

28. Qi, C.; Xiao, L.; Guo, J.; Wang, T. Low cost and highly reliable radiation hardened latch design in $65 \mathrm{~nm}$ CMOS technology. Microelectron. Reliab. 2015, 55, 863-872. [CrossRef]

29. Eftaxiopoulos, N.; Axelos, N.; Zervakis, G.; Tsoumanis, K.; Pekmestzi, K. Delta DICE: A Double Node Upset resilient latch. In Proceedings of the IEEE International Midwest Symposium on Circuits and Systems, Fort Collins, CO, USA, 2-5 August 2015; pp. 2-5. [CrossRef]

30. Eftaxiopoulos, N.; Axelos, N.; Pekmestzi, K. DONUT: A double node upset tolerant latch. In Proceedings of the IEEE Computer Society Annual Symposium on VLSI, Montpellier, France, 8-10 July 2015; pp. 509-514. [CrossRef]

31. Katsarou, K.; Tsiatouhas, Y. Soft error interception latch: Double node charge sharing SEU tolerant design. Electron. Lett. 2015, 51, 330-332. [CrossRef]

32. $\mathrm{Xu}, \mathrm{H} . ; \mathrm{Zeng}, \mathrm{Y}$. Circuit and layout combination technique to enhance multiple nodes upset tolerance in latches. IEICE Electron. Express 2015, 12, 1-7. [CrossRef]

33. Li, Y.; Wang, H.; Yao, S.; Yan, X.; Gao, Z.; Xu, J. Double node upsets hardened latch circuits. J. Electron. Test. 2015, 31, 537-548. [CrossRef]

34. Eftaxiopoulos, N.; Axelos, N.; Pekmestzi, K. DIRT latch: A novel low cost double node upset tolerant latch. Microelectron. Reliab. 2017, 68, 57-68. [CrossRef]

35. Wei, W.; Namba, K.; Kim, Y.; Lombardi, F. A novel scheme for tolerating single event/multiple bit upsets (SEU/MBU) in non-volatile memories. IEEE Trans. Comput. 2016, 65, 781-790. [CrossRef]

36. Li, H.; Xiao, L.; Li, J. High robust and cost effective double node upset tolerant latch design for nanoscale CMOS technology. Microelectron. Reliab. 2019, 93, 89-97. [CrossRef]

37. Yan, A.; Lai, C.; Zhang, Y.; Cui, J.; Huang, Y.; Song, J.; Guo, J.; Weng, X. Novel Low Cost, Double-and-Triple-Node-Upset-Tolerant Latch Designs for Nano-scale CMOS. IEEE Trans. Emerg. Top. Comput. 2021, 9, 520-533. [CrossRef]

38. Predictive Technology Model. Available online: http://ptm.asu.edu (accessed on 22 February 2006).

39. Weste, N.H.E.; Harris, D.M. CMOS VLSI Design: A Circuits and Systems Perspective, 4th ed.; Addison-Wesley: Boston, MA, USA, 2011; p. 318.

40. Yan, A.; Ling, Y.; Cui, J.; Chen, Z.; Huang, Z.; Song, J.; Girard, P.; Wen, X. Graduate School of Computer Science and Systems Engineering, Kyushu Institute of Technology, Fukuoka, Japan Quadruple Cross-Coupled Dual-Interlocked-Storage-Cells-Based Multiple-Node-Upset- Tolerant Latch Designs. IEEE Trans. Circuits Syst. I Regul. Pap. 2020, 67, 879-890. [CrossRef] 